\title{
La Artesanía de los muñecos llevada a la escuela
}

\author{
Macarena MORENO MORENO ${ }^{1}$ \\ Universidad Complutense de Madrid \\ narecama13@yahoo.es
}

Recibido: 01/03/13

Aceptado: $14 / 10 / 13$

\section{RESUMEN}

Este artículo recoge la experiencia de llevar la práctica de la artesanía al aula. Realizamos muñecos y adornos de lana y fieltro en una escuela pública de Guadalajara con una artesana de la zona. Así mismo hacemos un recorrido por las artistas que trabajaron muñecos y por la importancia del trabajo con las manos y la dramatización en la educación.

Palabras clave: Artesanía, títeres, dramatización, lana y fieltro, artistas de los muñecos, teatrillo. experiencia en el aula.

\section{Referencia normalizada}

MORENO MORENO, M. (2013). "La Artesanía de los muñecos llevada a la escuela". En Arteterapia: Papeles de arteterapia y educación artística para la inclusión social Vol.: 8. Páginas 107-122.

\section{SUMARIO}

Introducción: El arte como vínculo. Sophie Taeuber Arp, Maria Wassielief, Hannah Höch, Paúl Klee y otras artistas de los muñecos. ¿Qué es hacer muñecos? La importancia de la dramatización en el aula. La artesanía. La importancia de trabajar con las manos. La lana y el fieltro. La lana y su proceso de preparación. El fieltro. Descripción de la actividad. Posibles enfoques según la edad. Finalidades en las distintas edades. Representación de un teatrillo. Una experiencia en el aula. Taller de lana. La creación de los personajes. Materiales. Como se hace. Resultados. Bibliografía.

\section{The craftsmanship of puppets applied to schools}

\begin{abstract}
This article describes the experiences of bringing craftsmanship practice into the classroom. We dolls and ornaments and felted wool in a public school in Guadalajara with a craft area. Also do a tour of the artists who worked dolls and the importance of working with your hands and drama in education.
\end{abstract}

Keywords: Crafts. Puppets. Dramatization. Wool felt. Artists of the dolls. Theatre. Experience in the classroom.

\footnotetext{
${ }^{1}$ Dra. en Bellas Artes. Universidad Complutense Madrid. Artista y profesora de la UCM. Maestra. Especialista en pedagogía Waldorf.

www.macarenamoreno.es, http://arsartismac.blogspot.com/
} 


\section{CONTENTS}

Introduction: Art as a link. Sophie Taeuber Arp, Maria Wassielief, Hannah Höch, Paúl Klee and other artists of the dolls. What is making dolls?. The importance of drama in the classroom. Crafts. The importance of working with your hands. Wool and felt. Wool and its preparatory process. Felt.. Description of the activity. Possible approaches for age. Aims at different ages Representation of a little theater. A classroom experience. Workshop wool. The creation of the characters.Materials. As is done. Results. Bibliography.

\section{INTRODUCCIÓN. EL ARTE COMO VÍNCULO}

A comienzos del siglo XX una parte de las vanguardias artísticas promovieron el acercamiento de la nueva estética al mundo de los niños. Buscaban con ello contribuir a un cambio social, canalizado a través de la educación de las nuevas generaciones. Colectivos de artistas que con entusiasmo esperaban que sus propuestas estéticas se trasladaran a la sociedad para impregnar la vida cotidiana y, de esta manera, contribuir al origen de un nuevo estilo de vida. Como consecuencia, muchos artistas se dedicaron a diseñar muebles para niños, a ilustrar libros infantiles y a fabricar juguetes. A pesar de este pensamiento subyacente, fueron muchos los que realizaron juguetes simplemente para complacer a sus hijos o por el mero placer que les proporcionaba.

Hay artistas que lograron conjugar el constructivismo y la tradición para posibilitar un mejor acercamiento del arte moderno al mundo infantil, como Picasso, Paul Klee o Joan Miró, que crearon obras para los niños como una expresión más de una manera de mirar el mundo.

Marionetas, escenarios en miniatura, muñecos, juegos, muebles, libros... Los resultados del esfuerzo por integrar arte y educación fueron muy numerosos.

Este acercamiento de los artistas al mundo infantil y a la educación se ha ido dando a lo largo de la historia de muy diversas maneras, pero no todos los artistas recurrían a la realización de muñecos o figurillas por esa única razón. Los artistas que hemos seleccionado se caracterizan por tener un vínculo con la sociedad de compromiso, de cambio, de ruptura de límites, de crítica, de reivindicación de nuevos valores, de aportaciones estéticas.

Nos interesaba presentar el hecho de que la creatividad no entiende de límites y de cómo el artista es un ser humano de su tiempo y no solo representa el mundo en el que vive sino que interviene en él aportando su visión y crítica constructiva. De cómo a pesar de que casi todos ellos han tenido condiciones muy duras en sus biografías, su pasión por crear iba más allá de las penalidades y no dejaron de hacerlo en ninguna circunstancia a pesar de las dificultades.

Nos parece muy útil mostrar ejemplos de personas que han tenido una voluntad firme para crear, que han disfrutado con ello y que se han mantenido fieles a sus convicciones. 
Queríamos mostrar así mismo un enfoque diferente de la obra de artistas reconocidos como Paúl Klee o Hanna Höch cuya aportación al mundo de los títeres ha pasado más desapercibida y que nos es tan cercana al mundo infantil.

Otras propuestas surgen de la tradición popular, considerada por los educadores como elemento pedagógico de primer orden que, por ser transmitido de generación en generación, supone un punto de unión entre el adulto y el niño, al igual que el núcleo de apoyo para la conservación de la propia cultura y que en nuestra experiencia veremos junto a Belén Camacho, una artesana de nuestros días. La práctica de la artesanía de la lana resulta muy útil para llevar a la enseñanza en el aula, ya que va a permitir que niñas y niños experimenten con el material y puedan crear libremente disfrutando con todo el proceso.

\section{SOPHIE TAEUBER ARP, MARI WASSIELIEF, HANNAH HÖCH, PAÚL KLEE Y OTRAS ARTISTAS DE LOS MUÑECOS}

Hanna Höch .GOTHA, ALEMANIA 1889-1978. Artista plástica y fotógrafa integrada en el movimiento Dadá que utilizó principalmente como modo de expresión el fotomontaje. Se la considera pionera en esta técnica fotográfica. Con sus fotomontajes quiso dar una visión diferente de la mujer y denunciar irónicamente los roles tradicionales, siempre con un toque de humor e ironía. Son figuras humanas en las que los rasgos europeos se mezclan con los de culturas exóticas, como la africana o la japonesa. Estas figuras las representará también en muñecos y títeres, en ocasiones redibujará la imagen de la mujer con sus muñecas dadá. Con ellas nos solo reivindicaba una nueva mujer si no que denunciaba el comportamiento discriminatorio de muchos de sus compañeros artistas. Vivió una época en la que apenas existían mujeres artistas y le costó mucho ser considerada por sus compañeros varones.

Sophie Taeuber-Arp. DAVOS, SUIZA 1889-1943. Perteneció a una generación de mujeres activas en la sociedad. Mujeres independientes que habían recibido una educación superior, normalmente de familias de la clase media o alta, que ejercieron una gran influencia en la escena cultural de los años veinte y treinta.

A lo largo de su vida, concilió todo tipo de posturas encontradas en el arte, lo que permitió que en su trabajo se dieran la mano figuración y abstracción, dadaísmo y geometría, desorden y armonía, arte y artesanía.

Artista cuya creatividad sin fin logra desdibujar los límites entre arte y artesanía, participó en muchas representaciones de teatro con sus muñecos, formando parte así del auge que tuvo en Suiza el teatro de marionetas en los comienzos del S. XX.

Todos sus títeres llevan hilos, son de una delicadeza extrema y tienen un acabado definido formal y técnicamente. Su trabajo es un ejemplo de la incursión del artista en campos muchas veces olvidados o tenidos en menor consideración ya que se consideran más cercanos a la artesanía. 
Marie Vassilief. SMOLENSK, RUSIA 1884-1957. Encontró una forma artística más lucrativa que la pintura con la que encauzar su creatividad: la creación de muñecos satíricos, marionetas y vestuario. Creaba sus muñecos reciclando materiales, con lo que tenía a su alcance, reivindicando la riqueza artística de este tipo de materiales así como el estímulo de la imaginación. Sus muñecos-retrato, son muñecos de trapo creados con objetos variados que parodiaban a personajes reconocibles por sus contemporáneos: Matisse, Picasso, el marchante Zborowski... en el teatro Arcoíris de Paris.

Realizó también muñecos escultura, muñecos más abstractos, que representaban tipos y posiciones sociales y retratos mueble. Con estas creaciones, Marie Vassilief ironizaba sobre el mundo en el que vivió.

Paul Klee.MÜNCHENBUCHSE,SUIZA 1879-1940. Desarrolló su vida en Alemania, cuyo estilo varía entre el surrealismo, el expresionismo y la abstracción. Realizó numerosos juguetes para su hijo Félix, títeres en su mayoría. Los distintos materiales que utilizó en la fabricación de las marionetas, al igual que los que empleó en algunas de sus esculturas, son materiales de desecho de poco valor.

Sus títeres son de mano y tienen el aspecto e inmediatez del objeto hallado. Recuerdan a los collages dadaistas, y a los diseños característicos de los círculos de la Bauhaus. Los títeres le permiten dotar a su obra de cierto distanciamiento y sentido del humor con respecto a la complejidad humana.

Fueron muchos los artistas que pusieron su creatividad en la creación de marionetas y teatrillos, ocupación hasta entonces dejada de lado por considerarse mera artesanía alejada del Arte. Se fundaron varios teatros de títeres famosos como el de San Gallen, en el año 1903 en Suiza o el de la Escuela de Artes Aplicadas de Zúrich. En ellos se representaban obras con tanto esmero y nivel estético, se cuidaba tanto la música, la escenografía etc., que sería difícil establecer los límites del arte y la artesanía.

\section{¿QUÉ ES HACER MUÑECOS?}

El planteamiento del Arte como tal, es un planteamiento adulto. El arte infantil a pesar de su apariencia abstracta en ocasiones, es un arte narrativo, está al servicio de contar algo. Suele expresar cosas muy concretas y al igual que el niño cuenta en sus dibujos su experiencias: El viaje que hizo, cómo es su familia o los objetos con los que fantasea, cuando el niño o la niña juegan con muñecos, ponen en boca de ellos sus historias, la expresividad de los muñecos se funde con la personalidad del niño y mediante esta identificación los niños cuentan sus vivencias. El niño les transfiere su personalidad y se identifica con ellos. Este es el inicio del juego dramático.

Los títeres o muñecos cobran vida al salir a escena, una vida que es independiente del actor, es como si el muñeco tuviera vida propia porque el actor está oculto en la mayoría de los casos, quizá lo más importante desde el punto de vista 
de la expresión artística es esa identificación que se produce del actor con el muñeco.

El muñeco proporciona al niño la posibilidad de desarrollar su fantasía, de expresarse y no tanto para mostrarse ante un público sino para jugar.

A través del muñeco se produce una metamorfosis, un descubrimiento de su personalidad reprimida o inconsciente, son a la vez un medio de ocultamiento y de revelación. Una vez que el niño adopta al muñeco vuelca en él toda su afectividad: cuidados, confidencias, temores, frustraciones...y toma conciencia de ellos al verlos representados. Hace de vehículo mediador entre la intimidad del niño y entre cómo percibe la realidad externa.

El títere le proporciona la posibilidad de reinventar las experiencias según las emociones o ideas que el niño quiere expresar a través de él y a su vez puede dominar sus debilidades o ahuyentar sus miedos. En cierto modo recuerda al hombre primitivo que se servía de ídolos sagrados para protegerse de los peligros y dominar sus miedos.

Los títeres al igual que los cuentos de hadas son portadores de símbolos. "Antes del cambio de dientes, los cuentos que se cuentan a los niños tiene que tener como única meta: alegría, vitalidad, serenidad, buen humor. Después, el cuento tiene que dar al alma imágenes de la vida para querer hacer lo mismo"”.

Como portadores de símbolos los cuentos y muñecos permiten que los niños puedan asimilar de manera inconsciente lo que no son capaces de explicar verbalmente y que a su vez puedan expresar su mundo íntimo a través del muñecosímbolo. Podríamos decir por lo tanto que los títeres poseen valor terapéutico, educativo y psicológico, son un medio de proyección, de expresión y de resolución de conflictos. Sirven al educador para conocer el mundo íntimo del niño, son un gran instrumento pedagógico y un apoyo para el desarrollo psicosocial del niño.

\section{LA IMPORTANCIA DE LA DRAMATIZACIÓN EN EL AULA}

El ser humano siempre está necesitado de asombro y consuelo, busca vías para acceder al conocimiento sobre el enigma del mundo. El arte cumple esta función antropológica, ofrece conocimiento por la vía de la emoción. La obra artística ofrece a las personas una gran variedad para todos los gustos y sensibilidades, para aquellos que viven la dimensión estética como una necesidad vital.

El arte aporta luz a la rutina, a la realidad existencial, esa es su trascendencia.

La importancia educativa del teatro que hacen los niños es que en él se mezclan diversos tipos de arte infantil: decoración, escenografía, música, movimiento, diálogo y actuación. El teatro es una forma completa de creación.

\footnotetext{
${ }^{2}$ Véase el libro: Steiner,R (2002): La sabiduría de los cuentos de hadas. Madrid, Editorial R. Steiner $3^{\mathrm{a}}$ edición. Pag. 10
} 
El teatro para los niños es algo significativo, pedagógico y constituye un medio de expresión global a nivel artístico.

Si se realiza sobre la base del juego y la libertad expresiva favorece el desarrollo de las facultades individuales, impulsa la capacidad crítica, la socialización y la creatividad. Es una magnífica oportunidad para que en el aula se trabaje la afirmación personal, la diversión y la comunicación.

Lo importante no es el resultado, la calidad estética de la obra, ni siquiera el que los niños escriban historias, según Vigotsky lo importante es que los niños sean los autores, los que se ejercitan en la inventiva creadora.

En el teatro se funden aspectos plásticos con aspectos de expresión corporal.

Tal como cuenta en su libro Carlos Angloti'"'Existen dos factores, por un lado está la expresividad del muñeco, conseguida con una acertada construcción y la expresividad del actor que da vida al muñeco mediante el movimiento y la voz". Hay un tercer aspecto que es la historia que se cuenta, su trama dramática, el texto, los diálogos y la música. Los tres aspectos de la expresión artística, el actor, su tiempo y su espacio se funden en una expresión totalizadora de ahí su importancia en la educación artística.

Desde el punto de vista de la educación el aspecto más interesante del teatro es el aspecto expresivo, el teatro como juego, que los niños se introduzcan en un mundo de fantasía en el que puedan dar rienda suelta a su imaginación y expresarse en diversos lenguajes.

El origen del teatro está en el juego. Es un juego que nos permite detener el tiempo y recrear situaciones nuevas en un espacio mágico.

Permite que el niño pueda realizar una simulación de la vida y que al identificarse con los personajes, al encarnar otro papel, adquiera un conocimiento de sí mismo más profundo que el que le proporciona la experiencia diaria y pueda entender un poco mejor el mundo que le rodea.

El trabajo del teatro de títeres es un trabajo colectivo. Al plantearse el juego dramático de manera colectiva potenciamos que el niño avance en su proceso de socialización. La expresión dramática al ser una ficción proporciona renovación, conocimiento sobre uno mismo y puede ayudar a resolver conflictos.

Se pueden crear historias entre todos, que el grupo asuma una historia creada por uno, realizar improvisaciones, juegos de roles, dramatizaciones de cuentos tradicionales. Lo fundamental es que el niño sienta una invitación constante a crear, que le podamos abrir caminos a la fantasía.

Las historias deben tener emoción, tensión, sorpresas y para conseguir esto es importante que el niño se implique en la historia, que se la crea. El maestro puede ayudar motivando, ayudando a profundizar en la historia, añadiendo matices.

\footnotetext{
${ }^{3}$ Angoloti, C (1990): Cómics, títeres y teatro de sombras. Madrid, Ediciones de la Torre. Pag. 132
} 
Otro elemento importante es la determinación del espacio escénico, los decorados. Una vez más podemos dar rienda suelta a que el niño explore su creatividad con la guía del docente. El trabajo colectivo crea una dinámica interna que combina en un mismo espacio educativo múltiples actividades creativas de expresión corporal, plástica, rítmica, musical, elaboración de historias, construcción de muñecos, decorados, etc. Es interesante ver todas las propuestas y aclaraciones al respecto que ofrece Isabel Tejerína en su libro en el capítulo dedicado al niño actor.

\section{LA ARTESANIA. LA IMPORTANCIA DE TRABAJAR CON LAS MANOS}

La artesanía es una actividad que acompaña al ser humano desde sus comienzos. Ha sido definida como una técnica manual creativa, para producir individualmente, bienes y servicios y como tal siempre ha supuesto un provecho para la humanidad.

"La palabra artesano tiene en su forma un significado profundo: arte-sano, actividad que sana, que cura. Su práctica nos conecta con nuestra naturaleza, con los aspectos de nuestro ser que necesitan equilibrarse y nos remite en el uso de sus materiales a la naturaleza y a su eterna sabiduría"s.

Después del cerebro, las manos son el tesoro más grande del hombre y a ellas se debe el desarrollo de la artesanía. Las manos son un órgano fundamental y gracias a ellas podemos realizar actividades vitales para protegernos, alimentarnos, combatir y perpetuarnos pero también son un órgano de expresión a través del cual podemos construir, dibujar, modelar y hasta pensar.

El sentimiento que se genera cuando trabajamos con nuestras manos, el acto de transformar la materia en lo que luego va a ser nuestra obra de arte, es una experiencia maravillosa que nos llena de satisfacción.

La artesanía cuenta además con la peculiaridad de que es algo individual, personal, produce objetos únicos, diferentes, pocas piezas que no están fabricadas en serie y emplea las materias primas propias de cada país.

El trabajo manual nos aporta grandes beneficios ya que despierta nuestro lado más creativo y nos aporta bienestar psicológico, nos mantiene conectados con el mundo, nos permite dejar fluir nuestros sentimientos más profundos, contribuyendo al autoconocimiento, nos permite ser más desinhibidos y más comunicativos con los demás, nos hace tener un estado de armonía total, nos vuelve personas más perceptivas y agudiza nuestros sentidos, aumenta la autoestima y nos brinda satis-

\footnotetext{
${ }^{4}$ Tejerina, I (1994): Dramatización y teatro infantil. Dimensiones psicopedagógicas y expresivas. Madrid, Siglo XXI De España editores S.A.

${ }^{5}$ AAVV (1982): La artesanía en la sociedad actual. Barcelona, Salvat Editores. Pag. 54
} 
facción, aporta beneficios a nivel motriz llegando a solucionar problemas relacionados con ello y también excluye bloqueos emocionales y prejuicios.

Hubo un tiempo tras la revolución industrial, en que la actitud social era menospreciar todo aquello que reflejara ruralidad o sistema de vida tradicional y que simbolizaba atraso o estancamiento económico del que se pretendía salir, sin embargo el creciente interés de la sociedad actual por la artesanía nos invita a reflexionar sobre la confianza ciega que habíamos puesto en la bondad del progreso técnico-industrial y del crecimiento económico a cualquier precio. No está de más preguntarnos si este creciente interés de la sociedad por las actividades y oficios artesanos no responderá a una actitud, inconsciente o no, de rechazo o insatisfacción social al modelo de vida que nos ha deparado la sociedad industrial con sus prometedores proyectos de desarrollo.

Así vemos como en ocasiones se recurre a ella como terapia ya que permite a la persona reconciliarse consigo misma y superar muchos problemas al ponerse en contacto con la materia y con la naturaleza.

Lo cierto es que la artesanía potencia una sensibilidad social hacia la recuperación de nuestras raíces culturales e históricas y es importante que la escuela participe de esta preservación del patrimonio cultural mostrando la artesanía a las nuevas generaciones.

\section{LA LANA Y EL FIELTRO}

En la actividad que vanos a describir seleccionamos dos materiales fundamentalmente: La lana y el fieltro. Elegimos la utilización de la lana y el filtro para nuestra propuesta didáctica porque nos parece un material que raramente es utilizado en la escuela. Pensamos que llamaría la atención de las niñas y niños por su novedad, su tacto agradable y la facilidad de su manejo.

\section{La Lana Y Su Proceso De Preparación}

Trabajar con la lana requiere un proceso minucioso y prolongado.

Se parte de lana de oveja recién esquilada, se lava y se quitan todos los parásitos e impurezas, poniéndola en remojo en agua templada con un detergente para lanas. Hay que lavarla dos o tres veces con agua tibia sin frotar, sólo estrujándola. Quitar las hierbas y trozos de suciedad. Después hay que aclararla todas las veces necesarias hasta que el agua salga completamente limpia. Se puede envolver la lana en una toalla y meterla en la centrifugadora a poca velocidad. Finalmente extenderla sobre alguna superficie o colgarla en el tendedero para que se seque.

La lana así lavada, ya se puede utilizar para el relleno de muñecos.

El siguiente paso consiste en peinar la lana para ahuecarla y dejarla lista en vellones para utilizar. 


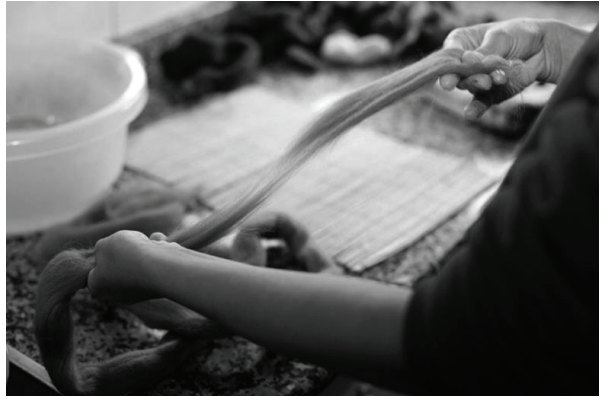

Foto 1

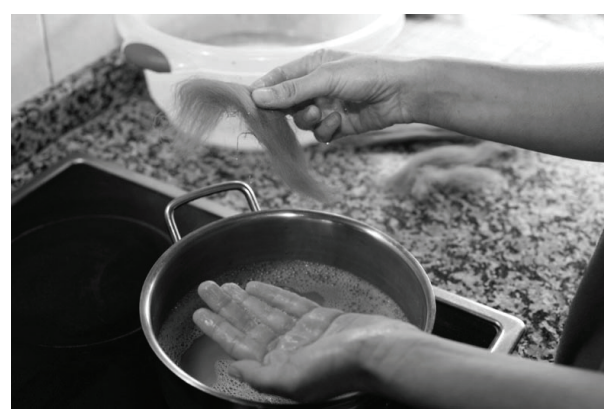

Foto 2

Los vellones ya ahuecados, se almacenan formando una montaña de lana.

Con la lana ahuecada se pueden hacer perfectamente pequeña figuras de animales y personas. Es muy elástica y no tiene partes más compactas que otras, permite poder rellenar y dar forma a la cabeza de una muñeca, por ejemplo.

\section{El Fieltro}

El fieltro es un tejido de lana, sin trama ni urdimbre que no se deshilacha y que se comercializa en una amplísima variedad de colores y diferentes grosores.

El filtro se utiliza para realizar los trajes de los personajes. Así como los adornos y elementos decorativos de los teatrillos.

Hay un tipo de lana, que se denomina lana para fieltrear y que permite crear superficies de fieltro fino para utilizar en los muñecos.

Para extender superficies de fieltro plano, se deshilachan pequeños mechones de lana peinada y se colocan unos sobre otros como las tejas, es decir, los mechones se ordenan superpuestos ligeramente solapados. La siguiente capa se extiende del mismo modo pero girándola $90^{\circ}$. Se colocan un mínimo de dos capas superpuestas un poco desplazadas, para que el fieltro no quede demasiado fino y poroso.

\section{DESCRIPCIÓN DE LA ACTIVIDAD \\ Posibles enfoques según la edad}

Este proyecto puede adaptarse a diferentes edades. La propuesta que hemos llevado a cabo ha sido realizada con niños de $1^{\circ}$ de primaria y con niños de $2^{\circ}$ ciclo de infantil pero puede adaptarse fácilmente a cualquier edad.

El hecho de asistir a un teatrillo, ver la técnica de la lana y el fieltro y crear ellos mismos sus propios objetos experimentando con materiales que nunca han utilizado, ofrece experiencias y conocimientos suficientes para todas las edades.

Con niñas y niños más mayores se pueden proponer objetos y muñecos más elaborados y con un acabado más preciso, dependiendo de las habilidades manuales y capacidades que los niños van adquiriendo; sin embargo entendemos 
que lo importante no es el resultado final del objeto acabado sino la experiencia obtenida, la percepción de los diferentes materiales, el respeto y la apreciación del trabajo de los compañeros y el conocimiento que les proporciona la actividad en sí.

\section{Finalidades en las distintas edades}

Las finalidades principales de la representación son:

- Conocer la existencia de otras culturas

- Sensibilizar a los niños sobre las dificultades de la emigración

- Aprender a respetar otras culturas y medios de vida

- Conocer las desigualdades de género que existen en otros países

- Que los niños y niñas se identifiquen con los personajes

- Buscar soluciones a los problemas de género y diferencia de culturas a través del juego y la imaginación.

Las finalidades principales de la actividad son:

- Hacer conocer la obra de artistas que trabajaron con muñecos

- Comprender todo el proceso de obtención de la lana

- Conocer la artesanía como oficio y medio de vida

- Conocer la técnica para crear un muñeco con lana

- Educar en valores

- Experimentar con materiales nuevos: lana y fieltro

- Crear su propio objeto con estos materiales conociendo la técnica y posibilidades expresivas que ofrecen

- Desarrollar la psicomotricidad fina y gruesa

- Intercambiar su experiencia con los demás respetando el trabajo ajeno

\section{REPRESENTACIÓN DE UN TEATRILLO. UNA EXPERIENCIA EN EL} AULA

La experiencia que describimos la hemos llevado a cabo con Belén López Camacho, una artesana que tiene su taller en El Casar, un pueblo de Guadalajara. Pudimos ver su taller y observar todo el proceso de elaboración de los muñecos. Con sus muñecos ella realiza teatrillos por todas las poblaciones de la zona. En esta ocasión la proponemos llevar la experiencia a la escuela del pueblo. La llevamos a cabo en el colegio público del Casar llamado "Los Arenales "en la provincia de Guadalajara. 
Belén ha preparado una representación con una historia suya para crear un teatrillo. Normalmente, una vez que tiene la historia estructurada, ensayada y los muñecos creados, suele representarla en diferentes lugares.

Realizamos la representación del teatro en primer lugar, como introducción a lo que luego será un recorrido por la elaboración de muñecos, el proceso de la lana y la actividad que realizarán las niñas y niños.

Los niños y niñas esperan impacientes el comienzo.

Es una clase de $1^{\circ}$ de primaria, compuesta por 23 niños y niñas, de los cuales 2 niñas son marroquíes, 1 niño rumano y una niña china.

La historia que les cuenta Belén y que representa con sus muñecos de lana, narra las peripecias de una niña marroquí al llegar a España y como a medida que va encontrándose con diversos personajes, va superando dificultades y haciendo amigos.

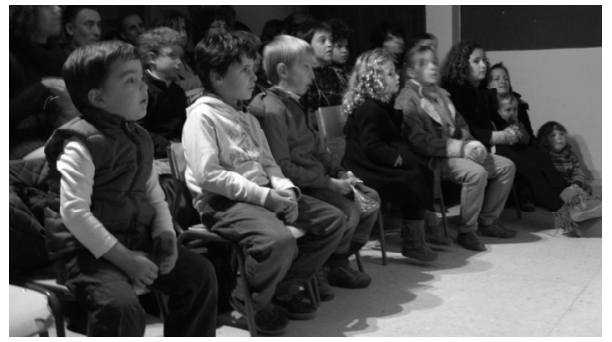

Los niños estuvieron boquiabiertos durante la representación que duró unos 25 minutos aproximadamente. Aplaudieron acaloradamente y junto con la maestra comentamos en grupo la experiencia. Las niñas marroquíes de la clase parecían especialmente emocionadas y pidieron a Belén que les dejara tocar la muñequita protagonista. Los niños preguntaron detalles de la historia y se sintieron interesados por aspectos de la cultura marroquí.

Días más tarde repetiríamos la experiencia en un aula de $2^{\circ}$ de infantil del mismo colegio y los niños recibieron la experiencia con muchísimo entusiasmo.

\section{TALLER DE LANA. LA CREACIÓN DE LOS PERSONAJES}

Una vez finalizada la historia, proponemos realizar un taller de lana en varias sesiones.

Primeramente hacemos un recorrido por los distintos artistas que han trabajado con títeres y muñecos, mostrándoles proyecciones de imágenes de los realizados por: Sophie Taeuber Arp, Maria Wassielief, Hannah Höch y Paúl Klee. Les hablamos de sus biografías y sus maneras de trabajar con diferentes materiales, de cómo ponían toda su creatividad e ingenio en ello y lo bien que lo pasaban realizándolos.

Los muñecos pueden ser de muchos tipos: Títeres de mano, con varillas, con hilos, de máscaras..Mencionaremos los más comunes. 
El títere de mano llamado también de guante o guiñol es manejado por una mano que se introduce dentro del títere. Generalmente la cabeza es rígida y se dirige con los dedos. Es fácil de manejar a partir de una edad en la que ya los niños tienen cierta habilidad y dominio sobre sus manos, alrededor de los 4 ó 5 años. Es el tipo de muñeco que creaba Paúl Klee.

También existen los títeres de dedos. Es una cabeza pequeña en la que se mete el dedo. Se pueden hacer de tela, papel mache, arcilla..

Existe un tipo de títere muy fácil de manejar por los más pequeños, los denominados títeres de manopla. Se utilizan metiendo toda la mano completa en la cabeza, el pulgar mueve la mandíbula inferior y los demás dedos la parte superior de la cabeza. Son muy fáciles de realizar, pueden crearse con un simple calcetín.

Los títeres de varilla tienen un sistema de sujeción y de movimiento que depende de varias varillas, generalmente con las que se mueven la cabeza y los brazos. Los hay más o menos elaborados hasta llegar a las tradicionales marionetas que se manejan con hilos desde arriba, como las que realizaba Sophie Taeuber-Arp o en las que se sustituye el hilo de la cabeza por una varilla rígida y de este modo quedan en movimiento únicamente los brazos, como algunas que realizó Hanna Höch.

Existen muchas maneras de crear muñecos y de combinarlos entre sí.

Los muñecos que creaba Marie Vassilief eran como pequeñas esculturas en las que no importaba tanto el movimiento sino el personaje que representaban en sí. Su función principal era la de ser una caricatura. Lo mismo sucede con las muñecas Dadá de Hanna Höch, eran además de una muestra de la creatividad de la artista, un medio para contar historias, para denunciar hechos, para imaginar y crear personajes de un mundo diferente.

Los muñecos o títeres que se propongan dependerán de la edad y de la habilidad manual del niño, pero en principio recomendaríamos técnicas fáciles en las que el proceso de elaboración sea rápido y gratificante para que los niños puedan jugar de inmediato y animarles a inventar con todo lo que se ofrece a su vista, que cada uno pueda crear su muñeco único y diferente.

Los materiales para la creación de muñecos son muchos y diversos y su utilización permite al niño descubrir posibilidades variadas a los objetos. Generalmente se utilizan materiales reciclables o asequibles que van desde el cartón, el corcho, hueveras, cajas de quesitos, guantes... Hasta materiales de todo tipo que podemos encontrar en cualquier parte como hacían Paúl Klee o Marie Vassilief. La lana y el fieltro son materiales sencillos que nos ofrecen muchas posibilidades y que veremos en la propuesta didáctica.

En el taller los niños y niñas conocerán las técnicas que emplea la artesana para preparar la lana y las diversas herramientas que utiliza para crear los personajes. Ella realizará un personaje para que puedan ver todo el proceso y les mostrará cómo crear el muñeco así como diferentes animales. Los niños tienen la ocasión de preguntar todo lo que se les ocurre.

A través de fotografías e historias podrán ver todo el proceso de transformación de la lana, hasta que está lista para crear los personajes. 
Primeramente para que se vayan familiarizando con el material y aprovechando la proximidad de las fiestas navideñas y los conocimientos que han adquirido sobre la artesanía de la lana, les proponemos hacer una bola de navidad y también la cabecita del muñeco que van a crear ellos.

Organizamos a la clase en grupos de 4 y 5 niños y repartimos material para cada grupo.

En esta actividad los niños y niñas van a tener la oportunidad de manejar el material con sus propias manos y compartir la experiencia con sus compañeros.

La segunda propuesta para que los niños trabajen la lana en mechones y en seco es que jueguen a hacer mariposas, para ello les ofrecemos el material ya preparado y los mechones de lana ya cardados.

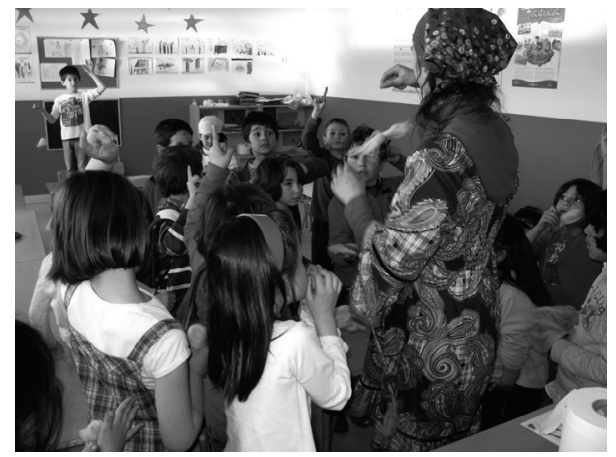

Foto 3

Finalmente les invitamos a crear su propio muñeco, un muñeco sencillo empleando la bola que hicieron como cabeza y vistiéndoles con fieltros y telas que les proporcionamos.

\section{MATERIALES:}

- Vellón en tonos diferentes. 20 ó $40 \mathrm{~g}$ aprox. para una bola de tamaño medio.

- Aguja de coser

- Hilo de costura de borde plateado o dorado

- Hilo de nailon

- Un recipiente con agua jabonosa

- Esterillas de bambú

- Toallas

- Limpiapipas

\section{CÓMO SE HACE}

1. Realizar la forma base de la bola con un vellón de lana, realizando un nudo en un extremo del vellón y enrollando alrededor. 
2. Colocar otro vellón de lana en la dirección contraria e ir enrollando de forma uniforme en todas las direcciones alrededor del núcleo compacto.

- Es parecido a enrollar lana formando un ovillo redondo.-

3. Sumergir la bola en la mezcla de agua jabonosa, hasta que aparezcan pequeñas burbujas.

4. Ir extendiendo sobre la bola mechones deshilachados de lana y fijarlos con el agua jabonosa. Ir añadiendo lana hasta obtener el tamaño deseado. Para compactar la bola, pasarla de una mano a la otra y hacerla rodar entre las manos con movimientos circulares.

5. Un vez que está la bola compacta se inicia el proceso de bataneado. Para ello, hacer rodar la bola sobre una esterilla de bambú. Hasta obtener el tamaño deseado y dejar secar encima de una toalla.

6. Una vez seca la bola se le pueden añadir motivos de adorno con hebras de lana de diferentes colores, cosidos con la aguja.

7. Finalmente el docente atravesará con aguja e hilo de nylon cada bola para poderlas colgar.

8. Para realizar las mariposas únicamente hay que separar mechones de lana ya preparados y combinarlos según el gusto de cada uno y atarlos por el centro.

9. Para la elaboración de muñecos podemos coser telas alrededor de la bola de lana o ir envolviendo la bola con mechones de lana diferentes hasta irle dando la forma que queramos. Para los cuerpecillos es aconsejable crear un esqueleto sencillo con limpiapipas e irlo envolviendo con mechones de lana.

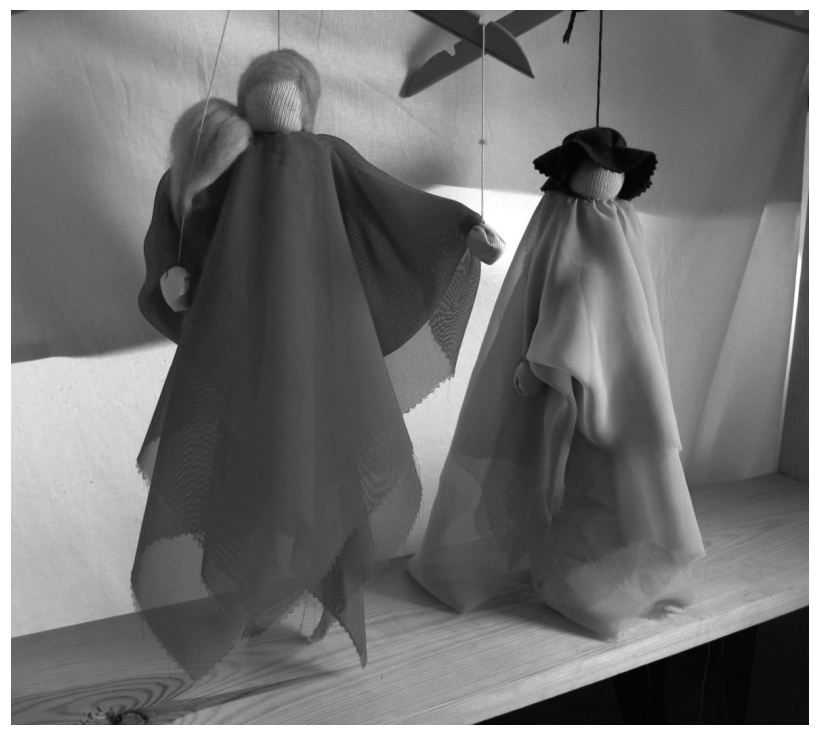

Foto 4 


\section{RESULTADOS}

Las niñas y niños estaban maravillados con el tacto suave de la lana. El contacto directo con materiales naturales les ha proporcionado una experiencia sensorial sin igual. Al principio se mostraban cautelosos a la hora de utilizar el agua, pero luego fueron adquiriendo seguridad y confianza.

Se les ha ofrecido la oportunidad de ver y comprender todo el proceso de la lana, desde que la oveja es esquilada hasta la realización de muñecos y adornos.

En esta actividad se trabaja tanto la psicomotricidad fina como la gruesa, imprescindible para su desarrollo.

El trabajo en grupo les ha permitido compartir la experiencia y aprender de los otros, tal como han visto en el cuento que se les narró al comienzo. Se han ayudado mutuamente y han compartido el material con respeto y cuidado.

Han experimentado el valor y el resultado del esfuerzo al crear su propio objeto.

Han conocido la artesanía como oficio y medio de vida.

Nuestro interés no ha estado puesto prioritariamente en el producto final, si no en el proceso y la experiencia individual creativa de cada niño, que ha sido muy gratificante para todos.

El profesorado y la dirección del colegio se han mostrado muy agradecidos por la iniciativa de llevar la artesanía a la escuela.

\section{REFERENCIAS BIBLIOGRÁFICAS}

ANGOLOTI, C (1990): Cómics, títeres y teatro de sombras. Madrid, Ediciones de la Torre.

AAVV (1989): Dadá y Constructivismo. Madrid, Centro de Arte Reina Sofía, Ministerio de Cultura.

AAVV (2004): Hanna Höch. Madrid, Centro de Arte Reina Sofía, Ediciones aldeasa

AAVV (1982): La artesanía en la sociedad actual. Barcelona, Salvat Editores.

AAVV (2009): Sophie Taeuber-Arp: Caminos de vanguardia. Málaga. Catálogo exposición .Museo Picasso Málaga. Edita MPM

FREYA JAFFKE (2002): Juguetes hechos por los padres. Editorial Rudolf Steiner.

GREGORIO, C (1998): Migración femenina. Su impacto en las relaciones de género. Madrid, Narcea. 
HETTINGER, G (2005): Lana y Fieltro. Barcelona, Drac.

LLEDÓ, G (2010): Hanna Höch. El arte como vínculo. Editorial Eneida. Colección Unidades didácticas.

SLADE, P (1983): Dramatización y teatro infantil. Madrid, Aula XXI, Santillana.

STEINER, R (2002): La sabiduría de los cuentos de hadas. Madrid, Editorial R. Steiner $3^{\mathrm{a}}$ edición.

TEJERINA, I (1994): Dramatización y teatro infantil. Dimensiones psicopedagógicas y expresivas. Madrid, Siglo XXI. De España editores S.A.

VIGOTSKI, L.S. (1982): La imaginación y el arte en la infancia. Madrid, Akal 